\title{
Ample Study and Review on Decision Support System with a Newly Proposed Model of DSS in Agriculture Sector
}

\author{
Puja Kadam \\ Asst. Professor, Computer Science, \\ Uka Tarsadia University, \\ Bardoli, Gujarat, India.
}

\author{
Sapan Naik \\ Asst. Professor, Computer Science, \\ Uka Tarsadia University, \\ Bardoli, Gujarat, India.
}

\begin{abstract}
Decision Support system is an application program based on computer that helps organizations and businesses to make decisions and help them to achieve their goals. In this paper we have described characteristics, capabilities, components and classifications and tools of decision support system. Apart from these we have proposed a new model of decision support system in the agriculture sector. This paper will be useful for the new comers who want to work in the field of DSS.
\end{abstract}

\section{Keywords}

Decision Support System, Agriculture sector, GIS.

\section{INTRODUCTION}

Decision support system is the area of Information system that focuses on the improvement and supportive managerial decision making for organizations and businesses. In late 1950s TPS came into existence and many clerical works like payroll, inventory was done using TPS. In 1960 the new emerging technology MIS came into existence. Since 1970 the study of Decision support system had aroused and day by day it is advancing and had become a routine use for business and organizational purposes.

The key applications where decision support systems are used are E-commerce, agriculture, Education, disaster management, knowledge management, Human Resource Management, Hospitality, Risk Management, Business Intelligence, and Artificial Intelligence etc.

There are different types of decision support systems. Some of the well-known decision support systems are as follows [2]:

DSS - Decision Support System

GDSS - Group Decision Support System

KMBDSS - Knowledge Management Based Decision Support System

IBDSS - Intelligent Based Decision Support System.

The future scope of decision support system is in robotics, artificial intelligence, business intelligence, data mining etc.

This paper is organized as follows: In section 2 we have given brief introduction of characteristics, and components of DSS. In section 3 we have included classification of DSS. In section 4 we have described about the tools that are used in decision support system and some emerging collaboration tools used for GDSS. In section 5 we have proposed a new model which shows how DSS is used in agriculture sector. Finally in section we have given conclusion and future work.

\section{CHARACTERISTICS OF DSS}

The major characteristics of decision support system by Alter are [10]

1. To facilitate decision processes DSS are specifically designed.

2. DSS should support rather than automate decision making, and

3. Quickly respond to the changing needs of decision makers.

2.1 The major characteristics and capabilities of decision support systems are as follows:

1. Supports semi structured and unstructured problems

2. Supports to managers at all levels.

3. Supports individuals, groups of an organization.

4. The decisions may be interdependent or sequential.

5. Supports all phases of decision making process.

6. Supports different styles and processes of decision making.

7. DSS are adaptable and flexible to the changing environment.

8. Different tools should be supported for decision making.

9. Easy to use and interactive.

10. Efficiency and effectiveness should be maintained.

11. The process should be controllable by humans.

12. Easy development by end users.

13. Data access

14. Web based and stand-alone integration

\subsection{COMPONENTS OF DSS:}

The major components of decision support system are as follows: 
Data Management Subsystem: The Data Management subsystem includes a database that contains relevant data for the situation and is managed by software called DBMS. The Data Management subsystem can be interconnected with the corporate data warehouse, a repository.

Model Management Subsystem: Is a $\mathrm{s} / \mathrm{w}$ package that includes financial, statistical, management science or other quantitative models that provide the system's analytical capabilities. Model base management system (MBMS) is a software for establishing, updating, combining, and so on (e.g., managing) a DSS model base

User Interface Subsystem: The component of a computer system that allows bidirectional communication between the system and its user. The user communicates with and commands the DSS through the User Interface Subsystem.

Knowledge-Based Management Subsystem: The knowledgebased management subsystem can support any of the other subsystems or act as an independent component. It provides intelligence to augment the decision maker's own. It can be interconnected with the organizations knowledge repository which is called the organizational knowledge base.

Below are the major points which have to be considered for the components of DSS.

1. Inputs: Factors, numbers, and characteristics which needs to be analyzed.

2. User Knowledge and Expertise: Inputs requiring manual analysis by the user

3. Outputs: Transformed data from which DSS "decisions" are generated

4. Decisions: Results generated by the DSS based on the criteria of user.

\section{CLASSIFICATION OF DSS:}

There are many ways to classify DSS application. Every DSS does not fits into one category, but it can be a mixture of two or more architectures.[7]

Holsapple and Whinston classify DSS into following five categories:

Text-oriented DSS: - Relies on knowledge coding, analysis, search, and retrieval for decision support. It includes DSS that are text based.

Example- Knowledge management System comes under text oriented DSS.

Database-oriented DSS: - They are involved with data and processing them into information and presenting the information to a decision maker.

Example -DSS developed in OLAP and data mining fall in this category.

Solver-oriented DSS: - DSS that are primarily involved with one or more optimization or simulation models that typically includes model formulation, model maintenance, model management in distributed computing environments and What-if analysis.
Example - Java Simulator can be considered as Solver oriented DSS.

Rule-oriented DSS: - It involves the application of knowledge technologies to address specific decision support needs.

Example - All artificial intelligence-based DSS fall into this category. Neural networks etc.

Compound DSS: - It is the most popular form of DSS. It is also known as Hybrid DSS. It involves Two or more than two DSS from the above four categories.

\section{TOOLS USED FOR DSS:}

The major tools which are used for decision support systems are balanced scorecards and dashboards.

Balance Scorecard: -The Balanced Scorecard was developed in early 1990s and was first introduced as a performance measurement system. It gradually evolved to become a management system that can serve as an integrating platform for the numerous management tools used within a company. [9]

The balanced scorecard helps businesses to see from four different perspectives.

1. Customer perspective.

2. Internal perspective.

3. Innovation and learning perspective

4. Financial perspective.

The balanced scorecard is both a performance measurement and management methodology that help translate an organization's financial, customer, internal process, and learning and growth objectives and targets into a set of actionable initiatives [5].

Dashboards:-

It is a tool that communicate the current health of the organization and its progress towards its strategic objectives [1].

Purpose of Dashboards:-

1. To communicate with the primary stakeholders about the current information

2. To help in the evaluation of organizational performance.

3. To provide an inclusive analysis of how the organization's achievement of its strategic objectives that effectively carry out the mission and vision of the organization.

4. To provide information about organizational routine compared to appropriate standards.

Scorecards and dashboards both provide visual displays of important information that is united and arranged on a single shelter so that information can be consumed at a single glance and easily explored. 


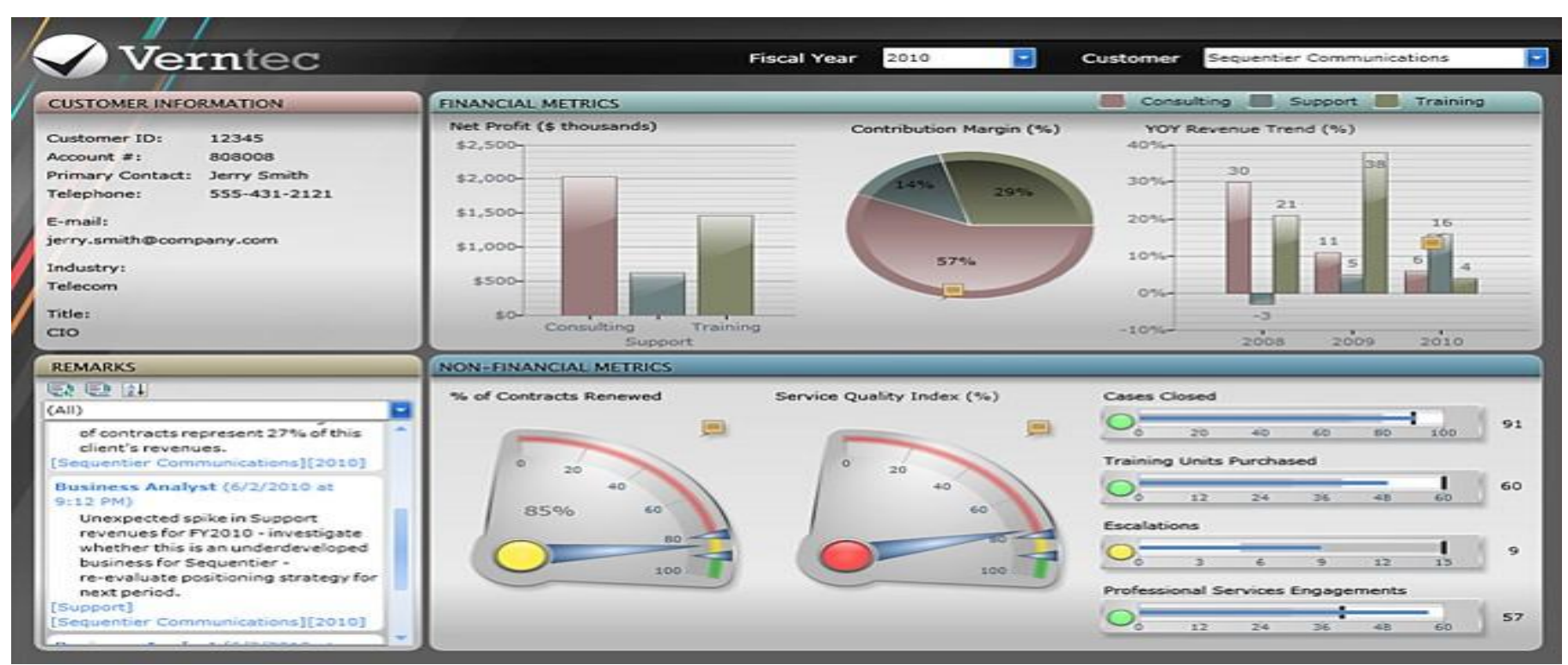

Fig 2: Dashboard

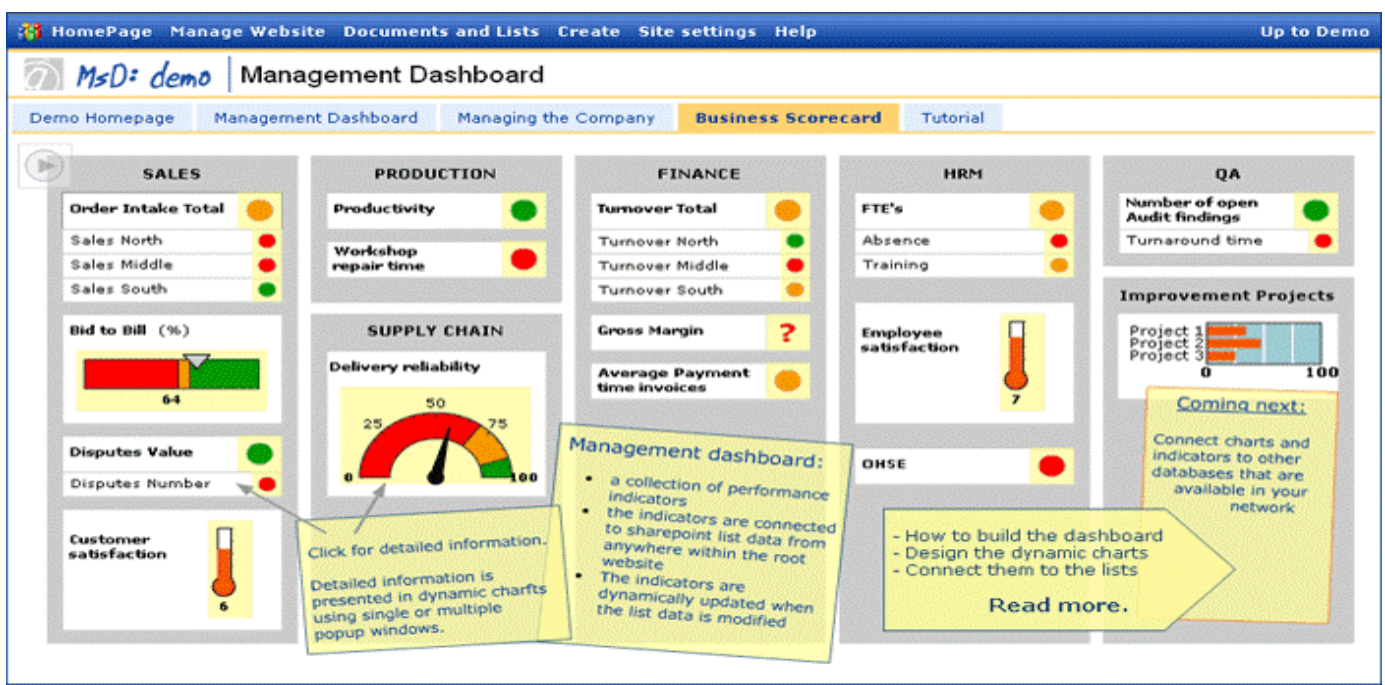

Apart from these there are some integrated software suites which are used by GDSS for taking decisions [1].

Lotus Notes was the first widely used GroupWare: Lotus Notes enables collaboration by letting users access and create shared information through specially programmed Notes documents. Notes provide online collaboration capabilities through Web conferencing on demand, work group, e-mail, etc.

Microsoft Windows Meeting Space and Live Meeting: -It is a real time collaboration package that includes application sharing, file transfer, text chat, and audio-video conferencing.
Groove Networks: -Groove virtual Office is a product from groove.

It is an end-user application for secure discussions, file sharing, meetings.

Groove Workspace enables spontaneous, online-offline collaboration that reduces project costs and speeds time-tomarket for products and services.

WebEx Meeting Center and Place Ware Conference Center:-WebEx meeting center is a pay-per-use groupware. It provides a low cost simplified way to hold electronic meetings over the Web. It integrates data, voice and video within a standard Web browser for real time meetings over the internet from any desktop or wireless handheld device. 


\section{PROPOSED MODEL OF DSS IN AGRICULURE SECTOR.}

Agricultural decision support systems are not being willingly accepted by all potential users. Use of Decision Support system should be there in each and every field to get the more précised and accurate results in the work which is done by the user.

In agriculture sector the DSS should be used which will help the farmers in growing the crops, vegetables etc. and will directly affect the people over the globe who are going to use the same.

The DSS which can be used in the field of agriculture are as follow:-

GIS: - GIS is the major DSS which is to be used in agriculture. Using GIS, we'll be able to know the location, the region where the farmers are going to harvest. Different kinds of data will be required further for the harvesting depending upon the region.

Geographic information system (GIS) software from ESRI is used to prepare and manage agricultural data and build geospatial snapshots of cropland [4].

Archetypally it includes soil and climatic data which helps us to explain differences and similarities in the production potential. Without GIS it is not possible to locate exactly the soil and the climatic condition as the region will not be available. Geographically, farm/field size and distance to the markets are similarly important. The data necessary for the agro-ecological zonification can have a general character. For example, a 1:50,000 soil survey forms an excellent basis.
To govern the expected production, crop growth simulation models are used. Detailed quantitative

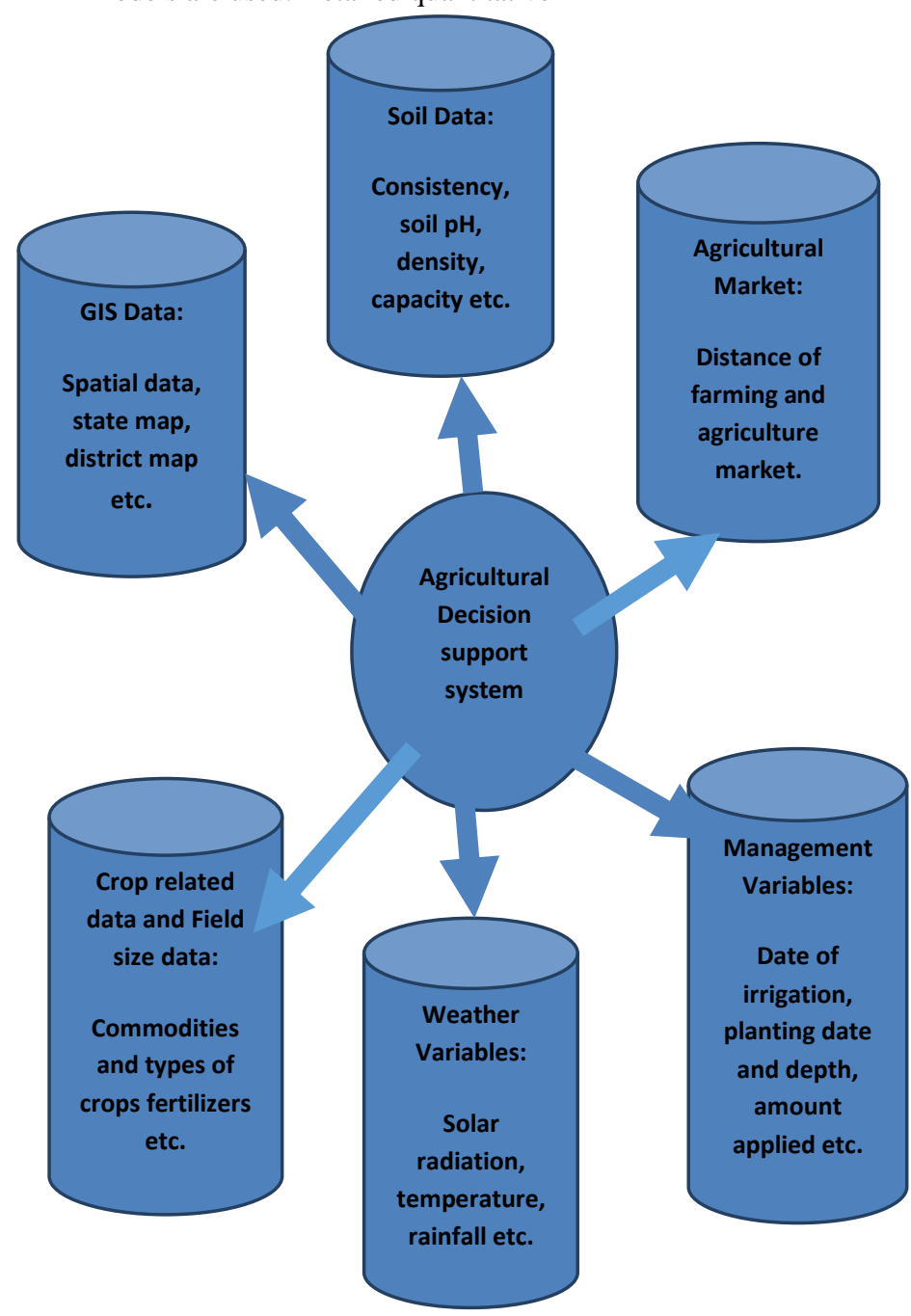


Data of soil and climate are necessary for the crop growth simulation model[4].

Enhancing a GIS with land-cover data layers has proved helpful to crop growers' associations, crop insurance companies, seed and fertilizer companies, farm chemical companies, libraries, universities, federal and state governments, and value-added remote-sensing/GIS companies [3].

Soil Characteristics: - The soil profile properties are defined for different layers down to the earth to at least the maximum depth of rooting.

The important properties for each layer includes: depth to the bottom of the soil layer from the surface, Volume of water content at the field capacity, density, organic content, soil $\mathrm{pH}$.

Understanding how soils form in the field and vary across landscapes is a critical skill for today's agronomists; therefore, it is an integral component of the curricula at Purdue University in Indiana. Students use GIS in the classroom and in the field to better understand soils and landscapes and to recognize geologic features that indicate different soil types [8].

Weather Variable: -The crop growth simulation model needs input daily values for rainfall, minimum and maximum temperature and solar radiation. Incoming radiation can be measured as the sunshine hours during a day, which can be converted to solar radiation estimates.

Below is the sample picture for knowing the weather condition using GIS.

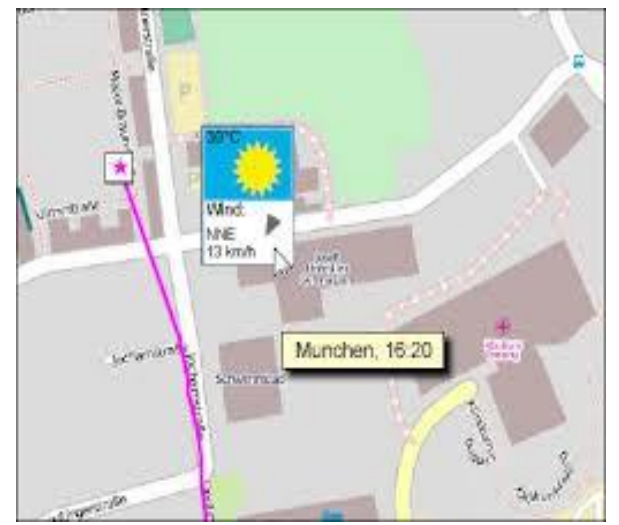

\section{Fig 4: Weather condition of a particular location}

Management variables: The management variables needed are: planting date, planting depth, plant population, row spacing. Irrigation date, amount applied, and type of irrigation.
Fertilizer application date, amount, method of application, depth of application, and type of fertilizer Previous crop residue dry matter amount, $\mathrm{N}$ and $\mathrm{P}$ content of the residue, depth of incorporation, and date of incorporation.

Fertilizer application date, amount, method of application, depth of application, and type of P fertilizer. Total and soluble P2O5 of PR sources.

Field size data: Field size is an important driving factor behind land management and land allocation decisions. Field size varies throughout the region. If the spatial variability is described by identifying a number of zones, one can specify the specific distribution per region. If data on field size are specified in the settings, the TOA software will sample field sizes. If not specified, one has to deal with field sizes in the economic models. For Carchi, an aerial photo interpretation yielded zones with a similar parcel distribution. On the basis of survey data, a log-normal distribution was used for parcel size in each of the three zones [6].

Cultivar-specific coefficients: - The crop growth simulation model pretends the effect of temperature and photoperiod on vegetative development, reproductive development and growth processes. These coefficients usually estimates the sensitivity of temperature, physiological maturity.

Reliable crop information is vital to the functioning of grain markets. It is used to inform decisions on planting, marketing, and policy. Applying GIS to the process of preparing crop estimates has improved accuracy while lowering costs [7].

Agricultural Market data: These is also an important factor for making decision in agricultural planning. The distance between the farming and the agricultural market should be known and calculated so that we can know if the farming is proper, the crop, vegetable production is good the distance should not be such that spoils the vegetative and the crop which was produced at the top grade.

Following is the sample picture for soil and watershed which is an important part in the agriculture field for cultivating the land and crop as well as vegetative production.

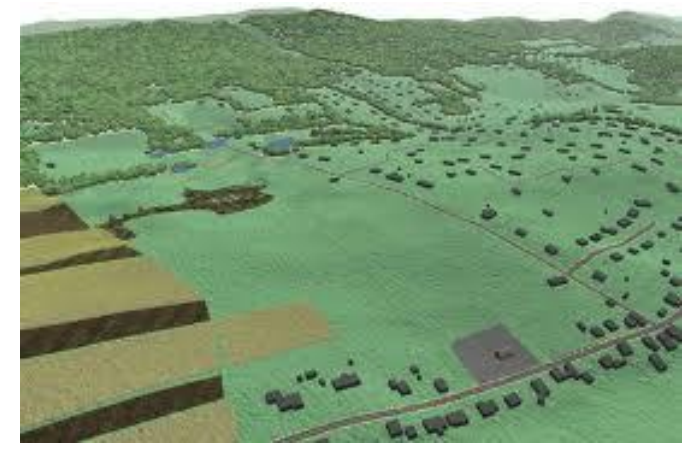

Fig 5: Using GIS the land for agriculture can be located. 


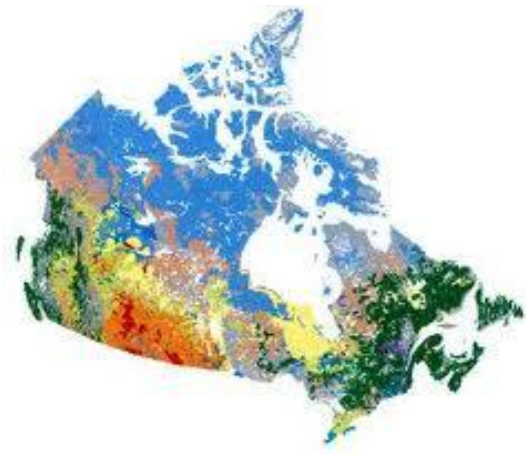

Fig 6: Sample picture of Soil map

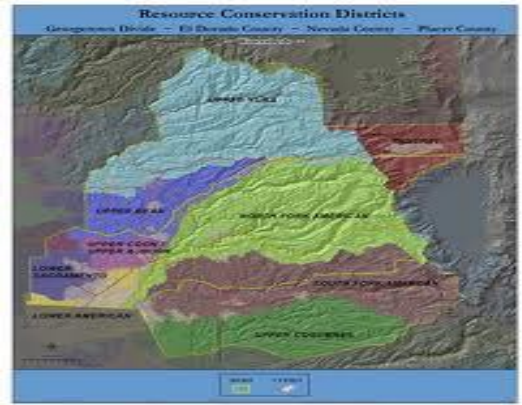

Fig 7: Watershed

Development of decision support systems on the following areas expediting Agricultural Resources Management are imagined using the state-of-the-art IT tools:-

Crop suitability based on feature endowment.

a. Land suitability assessment.

b. Land productivity assessment.

c. Population supporting capacity.

d. Land evaluation and land use planning.

e. Land degradation Risk assessment.

f. Land management,

g. Quantification of Constraints for land resources.

h. Agro-ecological characterization for research and planning.

i. Farming systems analysis and development.

j. Environmental impact assessment.

k. Water allocation for irrigation.

1. Water bodies planning system using watershed.

\section{CONCLUSION AND FUTURE WORK}

From the above proposed model and from the study of decision support system it can be concluded that for better vegetative growth and irrigation purpose we can use information technology. From the model it can be concluded that by using basic GIS features one can optimize the profit and the productivity of vegetation. Initially one has to invest a little bit in order to achieve the best quality of production but once it is done it will be a long-term benefit. In future we would like to implement the proposed model practically and would also like to study the effects of DSS in medical sector.

\section{REFERENCES}

[1] Efraim Turban, Ramesh Sharda, Durshan Delen, "Decision Support Systems and Business Intelligence Systems".

[2] Efraim Turban, Dorothy Leidner, Ephraim Mclean, James Wetherbe, "Information Technology for Management".

[3] Ramanathan Sugumaran, John DeGroote, "Spatial Decision Support Systems: Principles and Practices".

[4] GIS for Agriculture, ESRI, June 2009.

[5] Teijo Palander, Mari Toivonen and Sanna Laukkanen," GroupWare and Group Decision Support Systems for Wood Procurement Organisation”, May 2002.

[6] M.Narayana Reddy, N.H.Rao, "GIS Based Decision Support Systems in Agriculture", National Academy of Agricultural Research Management Ragendranagar.

[7] Prof. Mrs. J.R.Prasad, Prof. R.S.Prasad, Dr U.V.Kulkarni, "A Decision Support System for Agriculture Using Natural Language Processing (ADSS)", International MultiConference of Engineers and Computer Scientists 2008 Vol I, March 2008.

[8] J.J. Stoorvogel, J.M. Antle, C.C. Crissman, W. Bowen, "The Tradeoff Analysis Model Version 3.1: A Policy Decision Support System for Agriculture”, 2001.

[9] Robert S. Kaplan, David P. Norton, "The Balanced Scorecard - Measures That Drive Performance", 1992.

[10]http://dssresources.com/faq/index.php?action=artickel\&id $=13$ 